Background and Aims Leeds Teaching Hospitals Trust (LTHT) is one of the largest teaching hospitals in Europe providing local and specialist services to a million patients every year. We aimed to assess the clinical practice of peripheral nerve blocks (PNB) in our department by conducting a snapshot survey of its usage over a two-week period.

Methods Using an electronic survey form, we collected anonymised information from anaesthetists about the number and type of blocks, the theatre and hospital site, and the recipe used for each block. Theatre lists and operations were then analysed for this time period for the potential PNBs that could have been done for patients. We contacted consultants for them to share their expert local anaesthetic recipes for

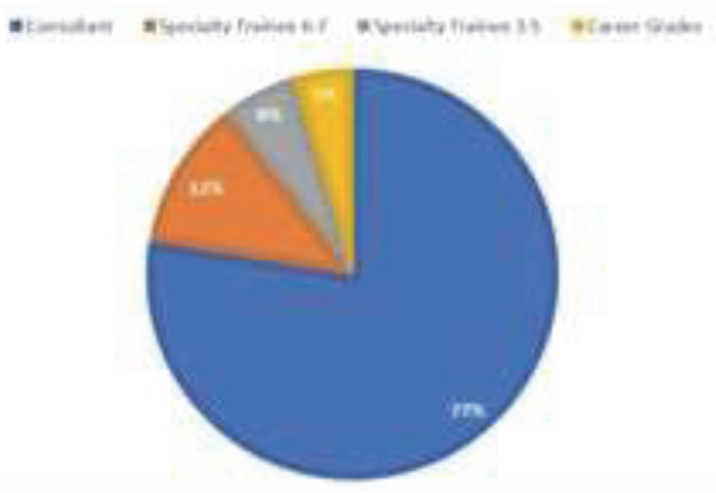

Abstract 203 Figure 1 Grade of anaesthetist performing nerve blocks (85 responses)

\begin{tabular}{|c|c|c|c|}
\hline $\begin{array}{l}\text { Peripheral } \\
\text { Verve Mbeds }\end{array}$ & $\begin{array}{l}\text { Blacks reported is } \\
\text { survey }\end{array}$ & $\begin{array}{l}\text { Estimated } \\
\text { potential P.VR }\end{array}$ & Amual cotimate \\
\hline Lowerr Limb & 89 & 175 & 3675 \\
\hline Choor land & 6 & 158 & 3318 \\
\hline Ordwhalwir & 11 & 70 & 1450 \\
\hline Frumad & 5 & 25 & 525 \\
\hline Cenved Plenus & 1 & 11 & 231 \\
\hline Total & 175 & 439 & 9219 \\
\hline
\end{tabular}

Abstract 203 Figure 2 Types of peripheral nerve blocks reported and estimates. Comparing the theatre activity of data collection period and the year leading to it gave as a multiplication factor of 21 for annual estimates

\begin{tabular}{|c|c|c|}
\hline Peripheral nerve Heck & Theatre lecatioss & Lecal anacothetic recipe \\
\hline 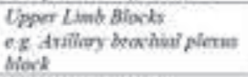 & $\begin{array}{l}\text { LGI Hand anil } \\
11,312 \text { and } 1166\end{array}$ & $\begin{array}{l}\text { 25. Xylocaine with adrenalige } \\
\text { is }-30 \mathrm{mls}\end{array}$ \\
\hline $\begin{array}{l}\text { Lonver Lind Blocks } \\
\text { ez Fascia Divara block }\end{array}$ & LOIII and 315 & $\begin{array}{l}0.37596 \text { leva.bopivacrioe } \\
20-30 \mathrm{mls}\end{array}$ \\
\hline 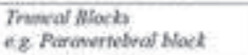 & $\begin{array}{l}\text { SNUH Clancelint } \\
\text { thestres: }\end{array}$ & 0 5\%-levo-bupiracaien; $15-20 \mathrm{mbls}$ \\
\hline 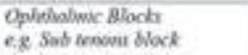 & $\begin{array}{l}\text { suth Cancellor } \\
\text { Dheatre I }\end{array}$ & $\begin{array}{l}\text { (1):11 } 246 \text { Lidocrise and } 0.546 \text { levo. } \\
\text { bupuvacaine; } 3.5 \mathrm{mbl}\end{array}$ \\
\hline 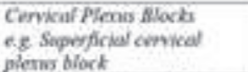 & Srutl beatse 6 & 0.25 Nevo bupivacaise: $10.15 \mathrm{mh}$ \\
\hline
\end{tabular}

Abstract 203 Figure 3 Representative example of the theatre map created for peripheral nerve blocks and local anaesthetic recipes for a typical Monday at Leeds Teaching Hospitals NHS Trust blocks performed in their regular practice. All data for this audit were collated using Microsoft Excel $^{\circledR}$.

Results We estimated 439 PNB could have potentially been performed however only 175 blocks were reported during this period. The majority of blocks were performed by consultants. Some responses suggested the need for additional training. We estimate approximately 9,219 PNBs are performed at Leeds every year. Figures 1-3 show detailed breakdown of our data collected including a 'theatre map' for PNB.

Conclusions LTHT provides excellent training opportunities for a variety of PNB. We appreciate there may have been a degree of under reporting by staff in this survey, but we will explore if there are any barriers in performing PNB for anaesthetists at Leeds. Creating a PNB database will facilitate safe clinical practice and support training in regional anaesthesia.

\section{BILATERAL RECTUS SHEATH BLOCK AS THE SOLE PERIOPERATIVE ANESTHETIC TECHNIQUE FOR OPEN SURGICAL GASTROSTOMY TO A PATIENT WITH DIFFICULT AIRWAY}

${ }^{1}$ F Sifaki ${ }^{*},{ }^{1} S$ Bagntasarian, ${ }^{1} \mathrm{P}$ Patsepas, ${ }^{2} \mathrm{O}$ Ioannidis, ${ }^{1}$ E Koraki. ${ }^{1}$ Georgios Papanikolaou, General Hospital of Thessaloniki, Thessaloniki, Greece; ${ }^{2}$ Aristotle University of Thessaloniki, Thesaloniki, Greece

\subsection{6/rapm-2021-ESRA.204}

Background and Aims Rectus sheath block (RSB) is a trunk block indicated for postoperative analgesia in minor surgical interventions. This case report describes the performance of RSB as the sole perioperative anesthetic technique to a patient with a difficult airway undergoing open surgical gastrostomy.

Methods We present the case of a 76-year-old, male patient undergoing open surgical gastrostomy so that enteral nutrition could be accomplished. The patient suffered from maxillofacial cancer. He had undergone a major maxillofacial surgery and 32 cycles of radiotherapy to the head and neck area. His airway was characterized as difficult, as he presented with a mouth opening of $1 \mathrm{~cm}$ and the structures of the upper airway were deformed. Our goal was to avoid general anesthesia and endotracheal intubation. We performed a bilateral RSB as the sole perioperative anesthetic technique with ultrasound guidance at T8 level, administering ropivacaine $0,5 \%$ and dexmedetomidine. When anesthesia of the surgical field was confirmed, the surgical procedure started and was completed without complications, with the patient remaining hemodynamically stable.

Results The bilateral RSB succesfully offered intraoperative anesthesia as well as sufficient postoperative analgesia to the patient.

Conclusions Trunk blocks are considered to be one of the cornerstones of modern anesthesia practices and can help the anesthesiologist provide a safe and stable anesthesia to highrisk patients. In our case, the performance of bilateral RSB to a patient with difficult airway undergoing open surgical gastrostomy, helped to completely avoid general anesthesia and also contributed to the patient's post-operative analgesia, increasing his satisfaction. 